\title{
Right Hemisphere Partial Complex Seizures: Mania, Hallucinations, and Speech Disturbances During Ictal Events
}

\author{
P. Gillig, ${ }^{*}$ J. C. Sackellares, and *H. S. Greenberg \\ Department of Psychiatry, College of Medicine. University of Cincinnati, Cincinnati, Ohio; and "Department of \\ Neurology. University of Michigan. Ann Arbor. Michigan, U.S.A.
}

Summary: A patient with right hemisphere complex partial seizures exhibited extreme emotional lability resembling mania, neologisms resembling those found in fluent aphasia, and hallucinations during ictal periods. The electroencephalographic and clinical findings in this case suggest that cortical and subcortical structures of the right hemisphere may play a role in mediating the expression of language content. Key Words: Epilepsy-Seizures - Behavior - Language disorders - Behavioral symptoms.
Expression of language content has been viewed as the function of the left hemisphere of the brain, and the right hemisphere is thought to be functionally related to emotional and melodic qualities of language and to general expression of affect (Mesulam, 1985; Shapiro and Danly, 1985). Ross and Mesulam (1979) discovered a loss of the usual variation of pitch, rhythm, and stress of emotional meaning ("speech prosody") without dysarthria or apraxia in two patients with supra-sylvian infarction of the right hemisphere. Subsequently, Ross (1981; 1986) found evidence that the organization of affective language in the right hemisphere seems to mirror the organization of propositional language in the left hemisphere. Research has also shown that in addition to melody in speech, the right hemisphere probably is involved in the acquisition of musical sequences in the musically naive (Bever and Chiarello, 1974) and that in one case, seizures with a focus in the right temperofrontal cortex were induced by playing a specific musical tune (Sutherling et al., 1980).

In the present case, a patient experiencing right

\footnotetext{
Received March 1987; revision accepted June 1987.

Address correspondence and reprint requests to Dr. P. Gillig at University of Cincinnati. 231 Bethesda Avenue, ML 559. Cincinnati, Ohio 45267, U.S.A.
}

hemisphere complex partial seizures displayed a marked exaggeration of pitch variability, rhythm, and stress of pronounciation during the ictal periods, with an extreme melodic quality to his speech and at times, actual singing of words and phrases. He also expressed neologisms similar in nature to those seen in patients with fluent aphasias, and experienced periods of psychosis with vivid auditory and visual hallucinations, all related to the right-sided ictal events.

\section{CASE REPORT}

The patient is a 32-year-old right-handed man without clinical evidence of mixed dominance for language (Benson, 1986), no history of perinatal trauma, head injury with loss of consciousness, schizophrenia, or mania. There was a long history of abuse of Valium, Placidyl, Triavil, Methadone, and alcohol, but not hallucinogens. He had been arrested for disorderly conduct 20 days before his transfer from jail to the hospital. He received no medication during the first 13 days in jail but spent the last 7 days of incarceration in the jail infirmary for treatment of Valium withdrawal. He was treated with low-dose benzodiazepines (diazepam 5-10 mg every $4-6 \mathrm{~h}$ ) while in the jail infirmary. During this 7-day period, although he remained afebrile and his 
blood pressure and pulse were within normal limits, he began to experience auditory hallucinations. He became paranoid, increasingly withdrawn, and believed that others could read his thoughts. The morning of his transfer he was described as unable to state his name or his whereabouts, and was found sitting naked under his bed on the concrete floor, smearing urine and feces on himself and screaming "unintelligible" phrases. He appeared to the staff at the jail to be agitated and depressed, saying he was "no good." He was transferred from the jail to a psychiatric facility, but while in the receiving area, suffered a generalized convulsion, and was transferred to a university hospital, where he was admitted to the neurology service.

Several hours after admission, the patient began to experience multiple discrete 30-s episodes of adduction of the left thigh, with left ankle extension, followed by clonic activity in the left lower extremity and mild clonic activity in the left upper extremity. At these times, the patient at first made verbal utterances alone, then seemed to experience discrete episodes of visual and auditory hallucinations, to which he responded verbally, with speech that took on a singing quality. There were serial alliterations, neologisms, and a few clang associations. He then became silent.

Laboratory evaluations, including complete blood cell count, platelet count, electrolytes, calcium, magnesium, creatinine, liver functions, and arterial blood gases were normal. Computed tomography (CT) scans of the brain done $24 \mathrm{~h}$ after admission and 5 days later, and CSF studies including protein, glucose, and cultures, were all normal. The patient was afebrile, and physical examination, including vital signs, was normal except during periods of extreme agitation when pulse and blood pressure were moderately elevated.

A routine 16-channel EEG was moderately to markedly abnormal, focal, and paroxysmal with frequent bursts of high amplitude sharp waves, spikes, and spike-waves in the right temporal regions, and occasional spread of the discharge to the right frontal and occipital areas. On two occasions during the tracing, when the patient clinically manifested twitching of the left upper and lower extremities, the EEG showed spread of the epileptiform discharge to the entire right hemisphere. There were no abnormalities over the left hemisphere during this tracing.

\section{Simultaneous EEG and closed-circuit video and audiotape}

The patient was monitored for approximately 45 min with a continuous EEG-Closed Circuit Televi- sion (EEG-CCTV) technique. The electroencephalogram was transmitted by FM radio transmitter. and eight EEG channels were recorded simultaneously on a split screen with a videotape recording of the patient's behavior. Scalp electrodes were applied such that bipolar recordings of cortical activity could be obtained across frontal, temporal, parietal, and occipital areas bilaterally. The patient's vocalizations were recorded simultaneously with the sound track of the videotape.

At the time the tracing was started, the patient was lethargic, distractible, but easily arousable. $\mathrm{He}$ displayed sporadic clonic activity of the left arm and leg, with lip-smacking. This was accompanied by a rambling speech pattern, except during arm and leg movement, when he was silent. When the patient vocalized, he spoke in normal English words or phrases but they were not formed into complete sentences. His rate of speech was normal. The simultaneous EEG tracing showed first a spike of approximately $75 \mu \mathrm{V}$ in the right anterior temporal area, followed by $7 \mathrm{~Hz}$ rhythmic right temporal theta activity, and then rhythmic slowing over the entire right hemisphere, which lasted several minutes. The tracing over the left hemisphere was within normal limits.

Following this, the EEG showed continuous nonrhythmic slowing, then $4-5 \mathrm{~Hz}$ rhythmic slowing in the right parietal and right posterior temporal regions. Coincident with the EEG change, the patient's vocalizations became louder and angrier in quality, with content showing sexual preoccupation. Then his level of arousal increased, he appeared agitated, and began to speak and sing in unintelligible phrases and apparent neologisms: "Back up there, get the four brothers for themself, pick on some kind of your own dear, spina, glitch, glitus, better visio...." At this point, the EEG began to show bursts of spikes, and sharp and slow-wave complexes in the right temporal area, and the patient suddenly began yelling unintelligible phrases. Following this, the EEG showed rhythmic slowing in the right temporal and parasagittal areas, and the patient displayed clonic activity of the left arm and leg, became silent, and was less arousable.

During the ictal discharges, even when the patient was speaking, he was unable to respond verbally or behaviorally to questions or commands, and was usually inattentive (Gloor, 1986a). As the EEG briefly returned to normal, he was able to state his name and the name of the city in which he was residing. As he again developed right temporal spike and slow-wave complexes on the EEG, which again spread to the right central area and were followed by right temporal slowing (over the course of 
$3 \mathrm{~min}$ ), he became unable to answer questions, and silent as he displayed clonic jerking of his left arm and leg. He then began yelling phrases that included neologisms: "I can't take it. Ain't nobody gonna leave you a listen, blisten, blong, we'll send that boy back out there. I' $m$ gonna send his mother. I'm gonna send him home." Sometimes neologisms and literal (phonemic) and verbal (semantic) paraphasias (Adreasen, 1979) were observed: "Bop, top, terranean, off with all and your mouth was all day and roof rock crick crack (then singing) tooth cross crick crock snow screaky." When the EEG briefly returned to normal, the patient again became more attentive and able to respond appropriately to some questions.

On only two occasions during the 45-min tracing were abnormalities recorded over the left hemisphere. On one occasion, lasting less than $4 \mathrm{~min}$, rhythmic slowing $(3 \mathrm{~Hz})$, first observed over the right parietal and posterior temporal areas, spread to the left hemisphere, although the right side remained more affected. During that period the patient displayed no clonic activity but may have been experiencing a visual hallucination ("we're starting to watch cartoons"). On the other occasion, a 5-s period of three to five $\mathrm{Hz}$ slowing was observed over the left central area. The patient was silent during this period. Otherwise, all recorded EEG abnormalities involved the right hemisphere only. The two periods of abnormality over the left hemisphere did not correspond with periods of speech disturbance. It was not clinically possible to determine whether the patient's sensorium was more clouded when the discharge spread to involve both hemispheres.

Later in the tracing, the EEG showed a 3-min period of some irregular $75-100 \mu \mathrm{V}$ sharp and slow wave complexes in the right central and right temporal areas without apparent involvement of the left hemisphere. The patient began "picking" at the air with his left hand, and then seemed to experience a frightening, formed visual and auditory hallucination. He stated: "Ma, get back down. I'm gonna shoot me one of these . . . if he gets back up. He's gonna find somewhere, somehow (yelling) someway (yelling louder). I heard the gun click (appearing frightened); bolt already! Aw, you guys are something else. A set up."

Following this study, the patient was treated with phenytoin and phenobarbital, but not with benzodiazepines. Within $24 \mathrm{~h}$, symptoms had cleared. He was alert and oriented, with no seizure activity nor abnormalities on neurological exam and no residual aphasia, word-finding difficulty, attention-span deficit, or memory loss. Fluency and comprehension of language, repetition, and naming were also intact.

\section{DISCUSSION}

In the present case, features usually associated with manic states were observed, including psychosis, extreme agitation, pressured speech, singing, occasional clang associations, and hyperprosody (Belmaker and Van Praag, 1980). The temporal coincidence of the EEG abnormalities and the affective and psychotic disturbances indicated that the disturbances were manifestations of ictal events. Alternate explanations of the episodes as being related to bipolar affective disorder, delirium, drug withdrawal, alcoholic hallucinosis (Victor and Hope, 1958), or a right hemisphere infarction causing an acute confusional state (Mesulam et al., 1976) are unlikely because (1) the patient had no prior psychiatric history, (2) the behavioral disturbances were episodic and temporally related to the ictal discharges of the electroencephalogram and resolved when treated by antiepileptic drugs, (3) physical examination was normal, (4) there were no significant metabolic abnormalities, and (5) CT scans were normal at 1 and 5 days. It is possible that the patient's seizure threshold may have been lowered if he had suffered a period of drug withdrawal while in the jail infirmary. However, the fact that the observed behavioral abnormalities were coincident with right hemisphere abnormalities on the EEG and resolved promptly when treated with antiepileptic drugs makes untenable the hypothesis that the behavioral and speech phenomena were manifestations of drug withdrawal alone.

The particular behavioral manifestations seen in the patient, including discrete periods of manic-like symptoms, are interesting in their relationship to right-sided ictal events. In a study of 50 patients with epilepsy, Flor-Henry (1969b) found that patients with partial complex seizures in whom manic depressive-like illness developed tended to have right-sided seizure foci. He postulated that both epilepsy and psychosis were manifestations of the same neuronal disorganization of the temporallimbic system. While Flor-Henry and other earlier researchers tended to attribute psychotic episodes, affective lability, and behavioral disturbances to cortical events (Sigal, 1976; Flor-Henry, 1969a; Wells, 1975), more recent evidence suggests that periods of extreme emotional behavior during seizures may be related to propagation of the discharges to subcortical structures (Wieser, 1983a, 1983b; Gloor, 1986b).

With regard to the observed speech disturbance, 
Mesulam (1985), Ross (1981), and others have previously argued that the right hemisphere plays an important part in expressing and comprehending the affective component of language by facilitating the expression of the melodic components of speech, and modulating pitch, rhythm, and stress of pronunciation. In the present case, the patient also had a disturbance of speech content, including neologisms. Surface electrodes demonstrated that the ictal discharge involved the cortex of the left hemisphere in only two very brief periods during the 45-min recording, and so it is unlikely that the speech disturbance was caused by spread of the discharge to left hemisphere structures. Although psychosis was observed also, the neologisms did not have the overly condensed and saturated-withmeaning quality sometimes attributed to schizophrenic neologisms (Hoffman et al., 1986) but rather resembled paraphasic distortions described in the context of fluent aphasia (Buckingham and Kertesz, 1974), although this distinction is controversial. Aphasia has not specifically been attributed to lesions of the right hemisphere except in cases of mixed dominance. Drake and Coffey (1983) observed speech arrest during right hemisphere complex status epilepticus, but correctly did not attribute this to aphasia over other factors, such as inattention, and in the present case, where the sensorium may also have been clouded, caution must be exercised in diagnosing aphasia. Nevertheless, in spite of these reservations, the findings of the present case suggest that cortical and subcortical structures (Crosson, 1985) of the right hemisphere may play a role in mediating the expression of language content, in addition to its affect, in an emotionally aroused patient, perhaps by virtue of the right hemisphere's better integration with subcortical mesiobasal-limbic structures (Joseph, 1982). Future research is needed to test this hypothesis.

\section{REFERENCES}

Andreasen NC. Thought language and communication disorders. Arch Gen Psychiatry 1979:36:1315-21.

Belmaker RH, Van Praag HB, eds. Mania: an e'volving concept. Jamaica, NY: SP Medical Scientific Books, 1980.

Benson DF. Aphasia and the lateralization of language. Cortex 1986:22:71-86.

Bever TG, Chiarello $\mathrm{K}$. Cerebral dominance in musicians and nonmusicians. Science 1974:185:537-9.

Buckingham HW. Kertesz A. A linguistic analysis of fluent aphasia. Brain Lang 1974:1:43-62.

Crosson B. Subcortical functions in language: a working model. Brain Lang 1985;25:257-92.

Drake M Jr, Coffey CE. Complex partial status epilepticus simulating psychogenic unresponsiveness. Am $J$ Psychiatry $1983 ; 140: 800-1$.
Flor-Henry P. Psychosis and temporal lobe epilepsy. Epilepsia 1969: a:10:363-95.

Flor-Henry P. Schizophrenic-like reactions and affective psychoses associated with temporal lobe epilepsy: etiological factors. Am J Psychiatry 1969b:126:400-4.

Gloor P. Consciousness as a neurological concept in epileptology: a critical review. Epilepsia 1986a:27:S14-26.

Gloor P. Role of the human limbic system in perception. memory and affect: lessons from temporal lobe epilepsy. In: Doane BK. Livingston KE, eds. The limbic system. New York Raven Press, 1986b:159-70.

Hoffman RE, Stopek S, Andreasen NC. A comparative study of manic vs. schizophrenic speech disorganization. Arch Gen Psychiatry 1986;43:831-8.

Joseph $\mathrm{R}$. The neuropsychology of development: hemispheric laterality, limbic language, and the origin of thought. $J$ Clin Psychol 1982:38:4-33.

Mesulam M-M, ed. Principles of hehavioral nearology. Philadelphia: F. A. Davis, 1985

Mesulam M-M. Waxman SG. Geschwind N. Sabin TD. Acute confusional states with right middle cerebral artery infarctions. J Neurol Neurosurz Psychiarry 1976:39:84-9.

Ross ED, Mesulam M-M. Dominant language functions of the right hemisphere? Prosody and emotional gesturing. Arch Norurol 1979:36:144-8.

Ross ED. The aprosodias. Arch Newrol 1981:38:561-9.

Ross ED. Modulation of affect and nonverbal communication by the right hemisphere. In: Mesulam M-M. (ed). Principles of behavioral ne'urology. Philadelphia: FA Davis, 1986:239-57.

Shapiro BE. Danly M. The role of the right hemisphere in the control of speech prosody in propositional and affective contexts. Brain Lang 1985:25:19-35.

Sigal M. Psychiatric aspects of temporal lobe epilepsy. J Nerv Ment Dis 1976:163:348-51.

Sutherling WW. Hershman LM, Miller JQ, Lee SI. Seizures induced by playing music. Newrology 1980:30:1001-4.

Victor $M$, Hope $J$. The phenomenon of auditory hallucinations in chronic alcoholism. J Nerv Ment Dis 1958:126:451-81.

Wells CE. Transient ictal psychosis. Areh Gen Psychiatry 1975:32:1201-3.

Wieser HG. Depth-recorded limbic seizures and psychopathology. Neuro/Sci Bio Behar Ro' 1983a:7:427-40.

Wieser HG. Electroclinical feanures of the psychomotor scizare. Boston: Butterworths. 1983b:193-205.

\section{RÉSUMÉ}

Chez un patient présentant des crises partielles complexes de l'hémisphère droit, nous avons observé pendant les crises une labilité émotionnelle évoquant le diagnostic de manie. des néologismes ressemblant à ceux de l'aphasie de Wernicke et des hallucinations. Nos constatation EEG et cliniques suggèrent que les structures corticales et sous-corticales de l'hémisphère droit peuvent jouer un rôle dans la médiation de l'expression du contenu linguistique.

(P. Genton, Marseille)

\section{RESUMEN}

Un paciente con ataques parciales complejos originados en el hemisferio derecho mostró una labilidad emocional extrema semejante a la mania, neologismos comparables a los que se encuentran en la afasia fluida y alucinaciones durante los períodos ictales. Los hallazgos clínicos y del EEG en este caso sugieren que estructuras corticales y subcorticales del hemisferio derecho pueden jugar un papel en la función del contenido del lenguaje expresivo.

(A. Portera-Sánchez, Madrid) 